\title{
Acceptability of a Dyadic Tai Chi Intervention for Older People Living With Dementia and Their Informal Carers
}

\author{
Yolanda Barrado-Martín, Michelle Heward, Remco Polman, and Samuel R. Nyman
}

\begin{abstract}
Exercise is effective in preventing falls among older adults. However, few studies have included people living with dementia and their carers and explored their experiences. The aim of this study is to explore what affects the acceptability of exercise interventions to better meet the needs of people with dementia and their carers as a dyad. Observations, field notes containing participant's and instructor's feedback, and focus groups with 10 dyads involved in Tai Chi classes for 3 or 4 weeks in two sites in the South of England were thematically analyzed to understand their experiences. Findings suggest that dyads' determination to achieve the benefits of Tai Chi facilitated their adherence, whereas a member of the dyad's low sense of efficacy performing the movements during classes was a barrier. Simplifying class content and enhancing the clarity of instructions for home-based practice will be key to support the design of future exercise interventions.
\end{abstract}

Keywords: community dwelling, dyad, exercise, falls, qualitative

Dementia is estimated to affect 46.8 million people worldwide (Alzheimer's Disease International, 2015), with advancing age being an important contributor to its prevalence (World Health Organization, 2015). Because of increasing life expectancy and the resultant increase in the number of individuals with dementia, this has become a matter of concern (World Health Organization, 2012). The progression of dementia has an increasing impact on the individual's cognitive and physical performance, ultimately resulting in more dependency toward their informal caregivers (Alzheimer's Society, 2015). This increase in dependency not only impacts on the person but also on the informal carer (henceforth "carer") and wider family and friends, potentially affecting social, health, and financial circumstances (Alzheimer's Research UK, 2015).

Falls have an additional and direct impact on an individual's autonomy and quality of life (National Institute for Health and Care Excellence, 2013). A variety of interventions (including Vitamin D supplementation, exercise, environmental, and multifactorial interventions) have been attempted to reduce the risk factors for falls among older adults living in the community. Exercise, including Tai Chi, and home safety interventions have been effective in

(C) 2019 The Authors. Published by Human Kinetics, Inc. This is an Open Access article distributed under the terms of the Creative Commons Attribution License CC BY NC ND 4.0, which permits unrestricted noncommercial distribution of the original work in any medium, provided the original work is properly cited, the new use includes a link to the license, and any changes are indicated. See https:// creativecommons.org/licenses/by-nc-nd/4.0/. This license does not cover any thirdparty material that may appear with permission in the article. For commercial use, permission should be requested from Human Kinetics, Inc., through the Copyright Clearance Center (http://www.copyright.com). Permission to adapt, build upon, or transform all or part of the article in a way that is copyrightable must be granted by the author(s) before the modified material can be distributed.

Barrado-Martín and Nyman are with the Dept. of Psychology, Bournemouth University, Poole, United Kingdom. Barrado-Martín, Heward, and Nyman are with Ageing \& Dementia Research Centre (ADRC), Bournemouth University, Poole, United Kingdom. Polman is with School Exercise \& Nutrition Sciences, Queensland University of Technology, Kelvin Grove, Australia. Address author correspondence to Yolanda Barrado-Martín at ybarradomartin@bournemouth.ac.uk. reducing the risk of falls (see Gillespie et al., 2012). However, in most of these studies, people living with dementia have been excluded even when they are more likely to experience a fall (Shaw, 2003). However, when people living with dementia in the community have been included, exercise-related activities have been shown to be potentially useful for this purpose of reducing around one-third the risk of falling (Burton et al., 2015). Tai Chi in particular shows promise for preventing falls among people living with dementia (Nyman \& Skelton, 2017). However, there is a lack of high-quality randomized controlled trials (RCTs) with blinded assessors that focus on exercise, including Tai Chi, among community-dwelling older adults living with dementia and their carer as a dyad.

Exercise interventions have been tested for their impact on behavioral and psychological symptoms in dementia, as well as on physical and cognitive function (i.e., Fleiner, Dauth, Gersie, Zijlstra, \& Haussermann, 2017; Hamilton et al., 2017; Öhman et al., 2016). However, recent systematic reviews of such studies have identified inconsistent results due to differences in settings (i.e., community vs. long-term care), exercise types (i.e., using one or different type of exercises as well as exercise alone or in combination with other interventions), and doses (Abraha et al., 2017; Laver, Dyer, Whitehead, Clemson, \& Crotty, 2016; Rao, Chou, Bursley, Smulofsky, \& Jezequel, 2014; Öhman, Savikko, Strandberg, \& Pitkälä, 2014). Lessons learnt from previous exercise interventions involving community-dwelling people living with dementia suggest that uptake facilitators are health-care professionals' advice (Chong et al., 2014; Suttanon et al., 2012), the provision of enough detailed information about the intervention (Frederiksen, Sobol, Beyer, Hasselbalch, \& Waldemar, 2014), and the use of positive phrasing in recruitment materials (Hawley-Hague, Horne, Skelton, \& Todd, 2016). Characteristics of the intervention such as a group-based format (Chong et al., 2014; Dal Bello-Haas et al., 2014; Hawley-Hague et al., 2016), the possibility of adapting the intervention to participants' needs (Chong et al., 2014), affordability (Chong et al., 2014; Hawley-Hague et al., 2016), and the abilities of the instructors to create a bond with participants influence their perceived attractiveness of the intervention (Hawley-Hague et al., 2016). 
Participants' characteristics also has an impact on acceptance in terms of personal motivations (Hawley-Hague et al., 2016), positive attitudes toward exercise (Chong et al., 2014; Suttanon et al., 2012), or the perceived benefits, including the value of research and the potential reduction of caregiver burden (Suttanon et al., 2012) and the expected impact on cognition (Chong et al., 2014).

Interventions designed to enhance well-being among people living with dementia and their informal carers are relatively recent (Van't Leven et al., 2013). Dyadic exercise interventions, where both the person living with dementia and the carer participate together, however, have been well received and feasible in the community (Chew, Chong, Fong, \& Tay, 2015; Suttanon et al., 2013; Yao, Giordani, Algase, You, \& Alexander, 2012; Yu et al., 2015). The involvement of both members has been found particularly relevant in exercise interventions to ensure safety and promote enjoyment (Dal Bello-Haas et al., 2014; Logsdon, McCurry, \& Teri, 2005; Suttanon et al., 2012; Yao et al., 2012).

Tai Chi is a mind-body exercise originated from China and based on the Taoist Philosophy (Fetherston \& Wei, 2011). Different styles of Tai Chi have been developed (i.e., Chen, Yang, Sun, $\mathrm{Wu}$ ) keeping most of the essential principles, but adopting different characteristics (i.e., intensity; Fetherston \& Wei, 2011). Previous research suggests that Tai Chi could be as effective and costeffective or more than alternative exercises targeting falls prevention among older people living with or without dementia, and could attract better adherence as a "normal" activity practiced by people of all ages and not just frailer older adults (Nyman \& Skelton, 2017). However, there is little research exploring the use of Tai Chi among people living with dementia in the community (Barnes et al., 2015; Burgener et al., 2008; Yao et al., 2012). Only Yao et al. (2012)'s pilot study (the most similar to this study, using an adapted simplified Yang Style form) used Tai Chi in isolation. In this study, participants attended $100 \%$ of the group sessions; however, those were only delivered twice a week for 4 weeks, whereas $84 \%$ adhered to the home-practice component, which lasted 12 additional weeks. In two other studies, adherence was around 72-75\% to classes delivered three times a week over 18 or 40 weeks, but Tai Chi was not delivered in isolation, which makes it difficult to differentiate what effects were due to Tai Chi (Barnes et al., 2015; Burgener et al., 2008). In all three cases as no qualitative methods were used, there is no way to explain the reasons for participants' engagement or disengagement with Tai Chi.

An underuse of qualitative methods has generally been observed in RCTs of health-care interventions (Drabble, O'Cathain, Thomas, Rudolph, \& Hewison, 2014). While more recently some RCTs have incorporated a qualitative component in their evaluation, this has not been the case in feasibility studies (O'Cathain, Thomas, Drabble, Rudolph, \& Hewison, 2013). To our knowledge, only one trial testing exercise in people living with dementia (Barnes et al., 2015) reported an amendment to their study protocol to implement qualitative data analysis, although results have not been reported to date. Acceptability has occasionally been reported by authors following their perceptions about participant's satisfaction with interventions or providing participants' anecdotal comments (e.g., Saravanakumar, Higgins, Van Der Riet, Marquez, \& Sibbritt, 2014; Yao et al., 2012). The need to listen to participants' opinions and perceptions regarding their involvement in Tai Chi interventions had already been highlighted (Saravanakumar et al., 2014), as it could help to understand the relevance of the intervention and identify ways of making it more appropriate for them. In this study, the acceptability of a Tai Chi intervention is explored using observational and focus groups data. This Tai Chi intervention is the pilot intervention phase of the TAi $\mathrm{ChI}$ for people with demenTia (TACIT trial). The aim of this study was to obtain information on the feasibility of a Tai Chi intervention for people living with dementia in the community, taking part together with an informal carer. The main objective was to identify any practical issues with the Tai Chi intervention that may reduce participants' acceptability of the intervention. Sharing the lessons learnt in this study could facilitate people living with dementia and their carer's adherence to Tai Chi and to similar exercise interventions designed for such dyads.

\section{Methods}

Prior to data collection for this study, ethical approval was received from the National Health Service (NHS; IRAS Project ID: 209193) and the trial was registered (ClinicalTrials.gov ID: NCT02864056).

\section{Recruitment Strategy}

Recruitment took place between October and December 2016. Potential participants were initially identified and approached by three NHS Trusts in the South of England, as well as by the research team using the Join Dementia Research website where people living with dementia can express their interest in taking part in research. In addition, the study was advertised locally, allowing potential participants to contact the research team directly to express their interest in the study. Once participants made initial contact (or after referral) to the research team, further information about the study was posted or emailed to them. Recruitment materials included a leaflet, a key facts sheet, and a participant information sheet. These materials provided information regarding balance, falls prevention, Tai Chi, and the implications of getting involved in the study for each member of the dyad. Confidentiality, voluntary participation, data protection, and consent procedure were also described within the participant information sheet. Potential participants were also provided with a visual representation of the different steps involved in the study. This study was presented as a falls prevention and balance improvement exercise, which was informed by the main outcome measures, and aim of the RCT. At least $48 \mathrm{hr}$ after receiving this information, an initial telephone screening was conducted to ascertain eligibility. A total of 53 people were contacted by the research team and of these 10 dyads (instead of 14 initially planned at this stage) were successfully recruited into the study (see Figure 1).

\section{Participants}

Demographic characteristics of participants included in the study are provided in Table 1 . The inclusion criteria for participants were a diagnosis of (mild to moderate) dementia, be aged 65 years or older, live in their own home, be able to practice standing Tai Chi, and have a carer available who would provide support during the assessments and at home and during the group-based Tai Chi classes. The exclusion criteria were people with Lewy Body dementia or Parkinson's disease, receiving end-of-life care, those with severe dementia symptoms according to the The MiniAddenbrooke's Cognitive Examination (M-ACE; Hsieh et al., 2015; cutoff point $\mathrm{M}-\mathrm{ACE}<15$ ) or sensory impairments, those already practicing Tai Chi, or those who would not be able to attend weekly classes. However, after finishing the pilot intervention phase, on reanalysis of M-ACE scores it was revealed that three participants 


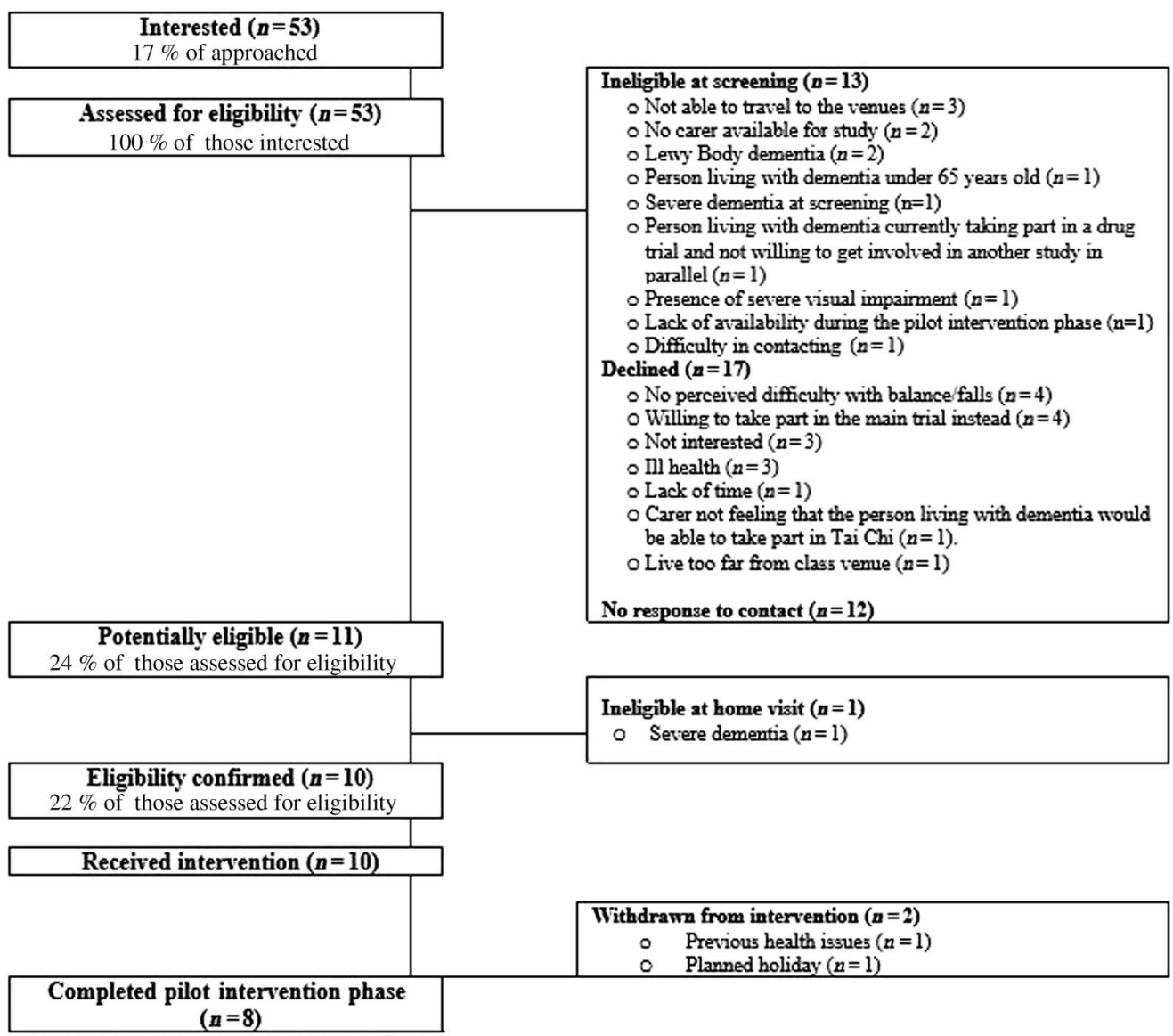

Figure 1 - Flow diagram of participant recruitment.

included in this phase of the study were in fact ineligible (scores between 10 and 15), which was reported to the sponsor. Nevertheless, all of the participants were able to take part in the classes and provide feedback and no one was put at risk from participating in the study. A subsequent request was sent to the research ethics committee to lower the M-ACE threshold score to 10 or above for the next phase of the study, which was approved.

\section{Procedure}

The 10 dyads recruited were split into two groups, according to their proximity to the venues. In Site 2, participants were invited to attend four classes (once a week) and practice at home for $20 \mathrm{~min}$ a day for 3 weeks as planned. The length of classes and home practice was set up to imitate the trial phase of the study where participants would be encouraged to do so to build up over $50 \mathrm{hr}$ of exercise dose (Sherrington et al., 2008). Because of the slower recruitment and restricted time frame, however, participants in Site 1 were invited to join the study for 3 weeks only and an extension was not offered. As the aim of this study was to obtain qualitative feedback on the experiences of participants to help develop the RCT phase, the impact of participants receiving three or four classes on research outcomes was not measured. The classes were to run over 4 weeks to allow the study of the acceptability of the classes, the home visit conducted by the instructor, and the home-based practice and the data collection methods used during dyad's involvement in the study in the short-term.
The Tai Chi course was specifically designed and made simple for people to follow, including several repetitions of the movements both in and between classes (during home practice). Corrections were given to all in class, without excluding any participant, and providing an explanation regarding the importance of ensuring a safe practice. Health and safety protocols were put in place to guide the instructor on what to do in the event of a fall during a class and to allow the instructor to know about participants' health conditions before the first class. Classes were led by a professionally trained Tai Chi instructor with experience of working with older participants living with and without dementia. Both pilot groups were led by the same instructor. Venues were chosen after checking their suitability against various criteria: size (able to accommodate between 14 and 20 people), maintenance conditions, accessibility by car and/or public transport, time slots availability, flexible booking, availability of on-site kitchen facilities, and general accessibility within the venue (i.e., lifts and toilets).

Both venues were spacious, had well-maintained wooden floors, heating systems, and used a combination of natural and artificial lighting. Classes were delivered during working days around midday on a weekly basis, following advice from the public and patient involvement advisory group that was involved in the TACIT trial's design (see Supplementary Material 1 [available online] for a description of this meeting). Participants were asked to arrive $10 \mathrm{~min}$ before the scheduled time of the class, take part in 45-min Tai Chi classes, and engage in conversation for 45 min after the Tai Chi class over a cup of tea/coffee and cake. 


\begin{tabular}{|c|c|c|c|c|}
\hline \multirow[b]{2}{*}{ Participant } & \multirow[b]{2}{*}{ Item } & \multicolumn{3}{|c|}{ Frequencies or means (SDs) } \\
\hline & & Site $1(n=4)$ & Site $2(n=6)$ & Total \\
\hline \multirow{42}{*}{$\begin{array}{l}\text { People living } \\
\text { with dementia }\end{array}$} & Gender & & & \\
\hline & male & 2 & 3 & 5 \\
\hline & female & 2 & 3 & 5 \\
\hline & Mean age $(S D)$ & $73.75(0.96)$ & $81.17(5.04)$ & $\begin{array}{l}78.20 \\
(5.39)\end{array}$ \\
\hline & Relationship status & & & \\
\hline & married/civil partnership & 3 & 5 & 8 \\
\hline & with partner & 1 & 0 & 1 \\
\hline & widowed & 0 & 1 & 1 \\
\hline & Current living situation & & & \\
\hline & living with family/friends & 4 & 6 & 10 \\
\hline & Level of education & & & \\
\hline & primary & 0 & 2 & 2 \\
\hline & secondary & 2 & 2 & 4 \\
\hline & higher education college/university & 1 & 0 & 1 \\
\hline & further education/professional qualification & 1 & 2 & 3 \\
\hline & Ethnicity & & & \\
\hline & White & 4 & 6 & 10 \\
\hline & Dementia type & & & \\
\hline & Alzheimer's & 3 & 6 & 9 \\
\hline & mixed Alzheimer's and vascular & 1 & 0 & 1 \\
\hline & $\begin{array}{l}\text { Mean number of months diagnosed with } \\
\text { dementia }(S D)\end{array}$ & $21(22.23)$ & $25.67(28.56)$ & $\begin{array}{l}23.80 \\
(24.97)\end{array}$ \\
\hline & Other chronic conditions & & & \\
\hline & yes & $\begin{array}{l}3 \text { (glaucoma, high pressure, and } \\
\text { headache/hypertension/ } \\
\text { sarcoidosis }^{\mathrm{a}} \text { ) }\end{array}$ & $\begin{array}{l}4 \text { (fibromyalgia }{ }^{\mathrm{b}} \text { and stroke/prostate cancer } \\
\text { and diverticulitis } / \text { neuralgia } / \text { hypertension) }\end{array}$ & 7 \\
\hline & no & 1 & 2 & 3 \\
\hline & Uses a walking aid? & & & \\
\hline & no & 4 & 6 & 10 \\
\hline & Mean prescribed daily medications $(S D)$ & $3.5(1.29)$ & $5.5(4.32)$ & $\begin{array}{c}4.7 \\
(3.47)\end{array}$ \\
\hline & Falls in the last year? & & & \\
\hline & yes & 0 & 1 (minor injury) & 1 \\
\hline & no & 4 & 5 & 9 \\
\hline & Falls in the last month? & & & \\
\hline & yes & 0 & 1 (minor injury) & 1 \\
\hline & no & 4 & 5 & 9 \\
\hline & Frequency of moderate PA practice & & & \\
\hline & everyday & 1 & 2 & 3 \\
\hline & 3 times per week & 1 & 0 & 1 \\
\hline & 2 times per week & 2 & 1 & 3 \\
\hline & weekly & 0 & 1 & 1 \\
\hline & rarely/never & 0 & 2 & 2 \\
\hline & Frequency of vigorous PA practice & & & \\
\hline & monthly & 1 & 0 & 1 \\
\hline & rarely/never & 3 & 6 & 9 \\
\hline
\end{tabular}


Table 1 (continued)

Frequencies or means (SDs)

Participant Item

Site $1(n=4)$

Site $2(n=6)$

Total

People living Previous experience practicing Tai Chi?

with dementia no

Mean confidence about being able to practice

Tai Chi for at least 20 min per day $(S D)$ e

Mean intention to practice Tai Chi for at least 20 min per day $(S D)^{\mathrm{f}}$

Carers

Gender
male
female
Mean age $(S D)$

Relationship with the person living with dementia spouse/partner other

Live with the person living with dementia yes

Relationship status

married/civil partnership

with partner

Current living situation

living with family/friends

Level of education

primary

secondary

higher education college/university

further education/professional qualification

Ethnicity

White

Previous experience practicing Tai Chi? no

Mean confidence about being able to practice

Tai Chi for at least 20 min per day $(S D)^{\mathrm{e}}$

Mean intention to practice Tai Chi for at least $20 \mathrm{~min}$ per day $(S D)^{\mathrm{f}}$

\author{
4
}

$1.75(0.96)$

$2.25(0.96)$

2

$69.25(1.5)$

4

0

4

3

1

4

0

1

2

1

4

4

$1.33(0.58)$

$1.33(0.58)$
6

$2.67(1.21)$

$2.17(0.75)$

2.2

4

6

72.40

(5.28)

$74.5(5.96)$

5

1 (niece)

9

1

10

9

1

10

1

3

3

10

1.78

(0.97)

Note. $\mathrm{PA}=$ physical activity.

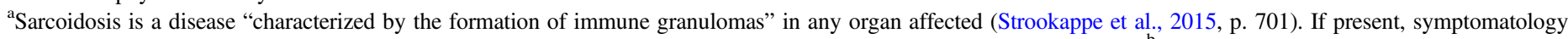

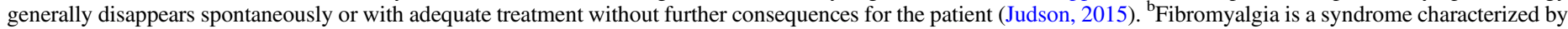
chronic "widespread pain" and possibly other physical (i.e., "muscle stiffness") and psychological ("memory and concentration" difficulties) manifestations (National Health Service, 2016). "Diverticulitis is an infection caused by bacterial accumulation in "small bulges that stick out of the side of the large intestine," which is generally cured after dietary, pharmacological, or (rarely) surgical intervention (National Health Service, 2017). ${ }^{\mathrm{d}}$ Neuralgia is the pain caused by nerve irritation or damage (Shelat,

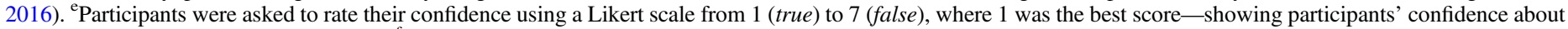
being able to practice for $20 \mathrm{~min}$ per day. ${ }^{\mathrm{f}}$ Participants were asked to rate their intention using a Likert scale from 1 (likely) to 7 (unlikely), where 1 was the best scoreshowing participants' intention to practice for at least 20 min per day.

Therefore, every session required participants' involvement for up to $90 \mathrm{~min}$. Before starting each class, participants had the chance to talk to other participants and the instructor. During the classes, participants generally practiced in silence and with no or only occasional verbal guidelines from the carer to the person living with dementia. Participants were expected to stand for the duration of the class to challenge their balance, but they were free to sit before and at the end of the session. Each class had the same structure formed by warm-ups, patterns, relaxation, and socializing. Classes consisted of copying the instructor's movements. Each pattern (formed by several movements) was slowly repeated two or three times by the instructor, depending on dyads' performance, while participants mirrored him. Participants responded mostly nonverbally (i.e., with laughs) to the instructor's jokes and interactions. Only in a few occasions, there was a verbal interaction between dyads and with the instructor. Classes developed in a friendly and relaxed atmosphere, where participants kept mostly focused on the instructor and received regular positive feedback. After the classes, participants interacted with each other and with the instructor, while enjoying some refreshments. 
In addition, dyads were asked to practice Tai Chi at home for 20 min a day after the first class. Participants were told that they could compensate their practice over the week (i.e., 1-day practice $30 \mathrm{~min}$ instead, and the next only 10 ; or split their $20 \mathrm{~min}$ practice in two slots of $10 \mathrm{~min}$ if this could fit better in their routines). A booklet was provided to act as a prompt for participants' home practice, reminding participants how to perform the movements. This booklet contained several pictures of each pattern, supported by explanatory text below each picture.

Dyads were supposed to receive a home visit from the instructor during the second week of their participation in the study to ensure a safe practice at home and complete an action and a coping plan. However, in practice, only six of 10 received this visit due to time constraints and various reasons. One of the dyads withdrew from the intervention after the first class; a second dyad joined the group a week later and the home visit had to be postponed because the person living with dementia was not feeling well, but then was never rescheduled because she was ill for the rest of her participation in the study. For the other two dyads, their location was quite far from the instructor's and they were not able to arrange a suitable time for both to meet. A noncompliance report was filled for this and sent to the sponsor. Nobody was injured during home practice and from this experience we learnt that for the future trial phase of this study, classes lead by the same instructor would need to start at least 2 weeks apart and home visits would only take place after the two first weeks of class practice. This way we could ensure enough time for the instructors to conduct these home visits without fail. In addition, information given to the participants has been revised to make clear that there is to be no home practice until the home visit is made. Although four dyads did not receive the intervention fully as per the protocol, they were not exposed to undue risk given the very safe intervention they are being asked to do (Tai Chi) in their home environment that they are very familiar with. We have not had any experience of there being any risks to account for in any of the home visits in the pilot intervention phase or the ones conducted so far during the RCT phase.

The action plan was introduced to identify a suitable time for home practice and the coping plan to develop strategies to overcome possible barriers to home practice (Chase, 2015). Action and coping plans are techniques used to facilitate behavior change
(National Institute for Health and Care Excellence, 2014), in this study to facilitate participants' practice of Tai Chi at home. The action plan is the document where both members of the dyad specify which days of the week, at what times (morning/afternoon/ evening), for how long, where specifically, and with whom will they practice Tai Chi. The coping plan is the document where both members of the dyad identify the anticipated barriers for practicing Tai Chi at home. For each barrier anticipated, they are requested to provide a way to overcome it and keep to the plan.

During the study period, one dyad from each site withdrew from the intervention ( $20 \%$ withdrawal rate). However, both dyads decided to carry on providing research data. As reflected in Table 2, six dyads attended all the classes offered and only one dyad attended less than $50 \%$ of the classes $(33 \%)$.

\section{Data Collection Process}

Field notes were used during participants' involvement in the classes to capture what was observed in the research context (Austin \& Sutton, 2014; Patton, 2013) and to record participant's and instructor's feedback. During the classes, qualitative semistructured observations were made over the two study sites following a semistructured checklist template (see Supplementary Material 2 [available online] for qualitative checklist). Each observation started with an initial description of the venue, participants' interaction, and spatial distribution in the room. To capture changes within sessions, observations were split into three blocks (first: $0-15 \mathrm{~min}$, second: 15-30 min, and third: 30-45 min). The observational schedule captured examples of participants' interactions, engagement (as interest and sustained attention; Kinney \& Rentz, 2005), attitudes toward Tai Chi, positive and negative affect (Watson, Clark, \& Tellegen, 1988), communication (as expressions of pleasure, sadness, self-esteem, and normalcy; Kinney \& Rentz, 2005), and psychological needs satisfaction (Deci \& Ryan, 2000). Data collected by the researcher observing the sessions were quotes (where possible) or a description of what was happening in the intervention context. Sessions were not video or audio recorded as the instructor opposed this. However, to ensure the appropriateness of the qualitative observation tool created for this study, two authors (first and last) took notes (following guidelines provided by the first author in

\section{Table 2 Dyads' Attendance to the Classes in the Pilot Intervention Phase}

\begin{tabular}{|c|c|c|c|c|c|c|c|}
\hline \multirow[b]{2}{*}{ Dyads } & \multicolumn{4}{|c|}{ Class number } & \multicolumn{3}{|c|}{ Totals } \\
\hline & First & Second & Third & Fourth & $\begin{array}{c}\text { Classes attended } \\
\text { per dyad }\end{array}$ & $\begin{array}{l}\text { Dyads' average } \\
\text { attendance }(\%)\end{array}$ & $\begin{array}{l}\text { Groups' average } \\
\text { attendance }\end{array}$ \\
\hline 01001 & Yes & Withdrawn $^{\mathrm{a}}$ & Withdrawn & N/A & 1 & 33 & Site 1 \\
\hline 01002 & Yes & $\mathrm{No}^{\mathrm{b}}$ & Yes & N/A & 2 & 67 & $75 \%$ \\
\hline 01003 & Yes & Yes & Yes & N/A & 3 & 100 & \\
\hline 01004 & Yes & Yes & Yes & N/A & 3 & 100 & \\
\hline 02001 & Yes & Yes & Yes & Yes & 4 & 100 & Site 2 \\
\hline 02002 & Yes & Yes & Yes & Yes & 4 & 100 & $83 \%$ \\
\hline 02003 & Yes & Yes & Yes & Yes & 4 & 100 & \\
\hline 02004 & Yes & Yes & Yes & Yes & 4 & 100 & \\
\hline 02005 & Yes & Yes & Withdrawn $^{\mathrm{c}}$ & Withdrawn & 2 & 50 & \\
\hline 02006 & $\begin{array}{c}\text { Not } \\
\text { recruited }\end{array}$ & Yes & Yes & $\mathrm{No}^{\mathrm{d}}$ & 2 & 50 & \\
\hline $\begin{array}{l}\text { Dyads attending } \\
\text { each class }\end{array}$ & 9 & 8 & 8 & 4 & & & \\
\hline
\end{tabular}

Note. ${ }^{\mathrm{a}}$ Due to previous health issues. ${ }^{\mathrm{b}}$ Due to a traffic accident blocking traffic. ${ }^{\mathrm{c}}$ Due to planned holiday. ${ }^{\mathrm{d}}$ Due to illness. 
an observational codebook) during sessions organized in Site 1, which were later compared to refine the observational data collection tool. At the end of each class, during the $45 \mathrm{~min}$ allocated to socialize, the first author interacted with the participants and the instructor individually and they provided their feedback about the session. This feedback was not audio recorded but the researcher took notes, while participants were providing their feedback or immediately after to avoid altering their accounts.

Focus group data were collected immediately after the last class (third or fourth depending on the site) and both lasted around $1 \mathrm{hr}$ taking place in the same venue as the Tai Chi class. All dyads attending the last class $(n=7$, three dyads in Site 1 and four dyads in Site 2) were involved in these focus groups. Two researchers facilitated each joint dyadic focus group (last and first authors in Site 1 and first and third in Site 2) and ensured the focus group schedule was followed. Topics covered included (see Supplementary Material 3 [available online] for focus group schedule) experience of taking part in Tai Chi classes and practicing Tai Chi at home, their willingness to continue, and their experience of taking part in research. This was audio recorded and professionally transcribed verbatim, to ensure the accuracy of participants' accounts. The first author attended all the sessions and was present in both focus groups. This researcher was in touch with participants weekly, so they were sharing their experiences with a familiar person.

\section{Ethical Issues}

Because of the progressive nature of dementia, process consent procedure was followed (Dewing, 2008), meaning that participants were verbally asked about their willingness to carry on taking part in the study at key points in the study, as well as the researcher looking for verbal cues that confirmed consent to participate.

During the data collection process, participants were informed that any data collected would be anonymized so their identities or any personal details would not be disclosed, and participants' nonverbal communication, particularly for those living with dementia, was checked during their interactions with the researchers. Participants provided informed consent to take part in the study and focus group during the baseline home visit, when they were asked to summarize back to the researcher what the study was about and what they would be doing as part of their participation in the study to check their ability to provide informed consent. However, to ensure their willingness to continue taking part in the study, process consent was sought at each interaction with the researcher. This was also verbally checked before and after the focus group. Should any participant have declined to carry on with their participation in the study, up until the point when their data would have been anonymized, their data would have not been analyzed. During the focus group, all participants were given an equal opportunity to share their experiences, with occasional direct invitations from the researcher to contribute to the conversation. To facilitate the involvement of participants living with dementia in the conversation, printed copies of focus group questions were provided in A4.

\section{Data Analysis Strategy}

Thematic analysis was used to identify common trends in systematic qualitative observations of the classes, field notes containing participants and instructor's views during their involvement in the study, and the content of the focus groups. Methodological (observation, feedback, and focus group) and data sources (participants, instructor, and researchers) triangulation were used to ensure credibility. Data were analyzed together following the six steps described by Braun and Clarke (2013) for thematic analysis: (a) audio files from focus groups were professionally transcribed verbatim, double checked, and anonymized (UK Data Archive, n.d.); (b) reading and rereading the transcripts to get familiar with the data; (c) coding all the data sets inductively, looking for salient units of meaning (Saldaña, 2016) in the manifest content expressed by participants, a codebook was developed with inclusion and exclusion criteria and examples for each code. A large number of codes were identified after this process and, after revision, very similar codes were merged; (d) themes were searched among the codes; (e) themes were reviewed to make sure they were representative of the codes contained; and (f) themes were defined and named. Data sets and the analytical process were managed using NVivo.11 (QSR International Pty Ltd., Doncaster, Victoria, Australia) (QSR International Pty Ltd, 2015). One author (first) coded the whole data set, and once the initial codes had been identified and refined (merging very similar codes), a coding booklet was developed. This booklet was provided to the second author, who double coded $10 \%$ of each type of data collected to enhance rigor. Coding was compared to refine the coding framework.

\section{Results}

The intervention was well received by the majority of participants (nine of 10 dyads) who expressed a willingness to carry on practicing Tai Chi after the study (see Table 1 for participants' characteristics). The remaining dyad was unable to continue participating in the pilot and withdrew after the first class due to health issues.

Two main themes were identified: intervention's characteristics and participants' reactions to the intervention (as reported in Table 3). Direct quotes presented contain participant identification numbers and a " $\mathrm{C}$ " when mentioned by a carer or a "P" if was mentioned by a person living with dementia. An "O" indicates this was heard during an observation or observed and described by the researcher, "FG" in the context of a focus group, and "F" when providing feedback at the end of the class. A summary of barriers, facilitators, and improvements suggested to enhance the acceptability of the intervention by participants, the instructor, or the research team is provided in Table 3.

\section{Intervention's Characteristics}

All subthemes contained by this overarching theme relate to the way the intervention was (a) delivered by the instructor, including the way he engaged with participants, built rapport, reassured participants, and tailored the intervention to meet participants' needs and (b) practiced by participants in terms of class- and home-based Tai Chi practice.

Instructional methods. All participants valued the instructor (see Table 3 for example quotes). Both people living with dementia and their carers stated that they were able to understand him as he was using clear speech and a calm tone of voice. During the classes, the instructor made use of examples from his private life to create rapport with participants (i.e., sharing comments made by his daughter), and also used examples from everyday life to describe the movements during the classes (i.e., "is like drinking a cup of tea" $[\mathrm{O}])$. He regularly provided positive feedback during the 


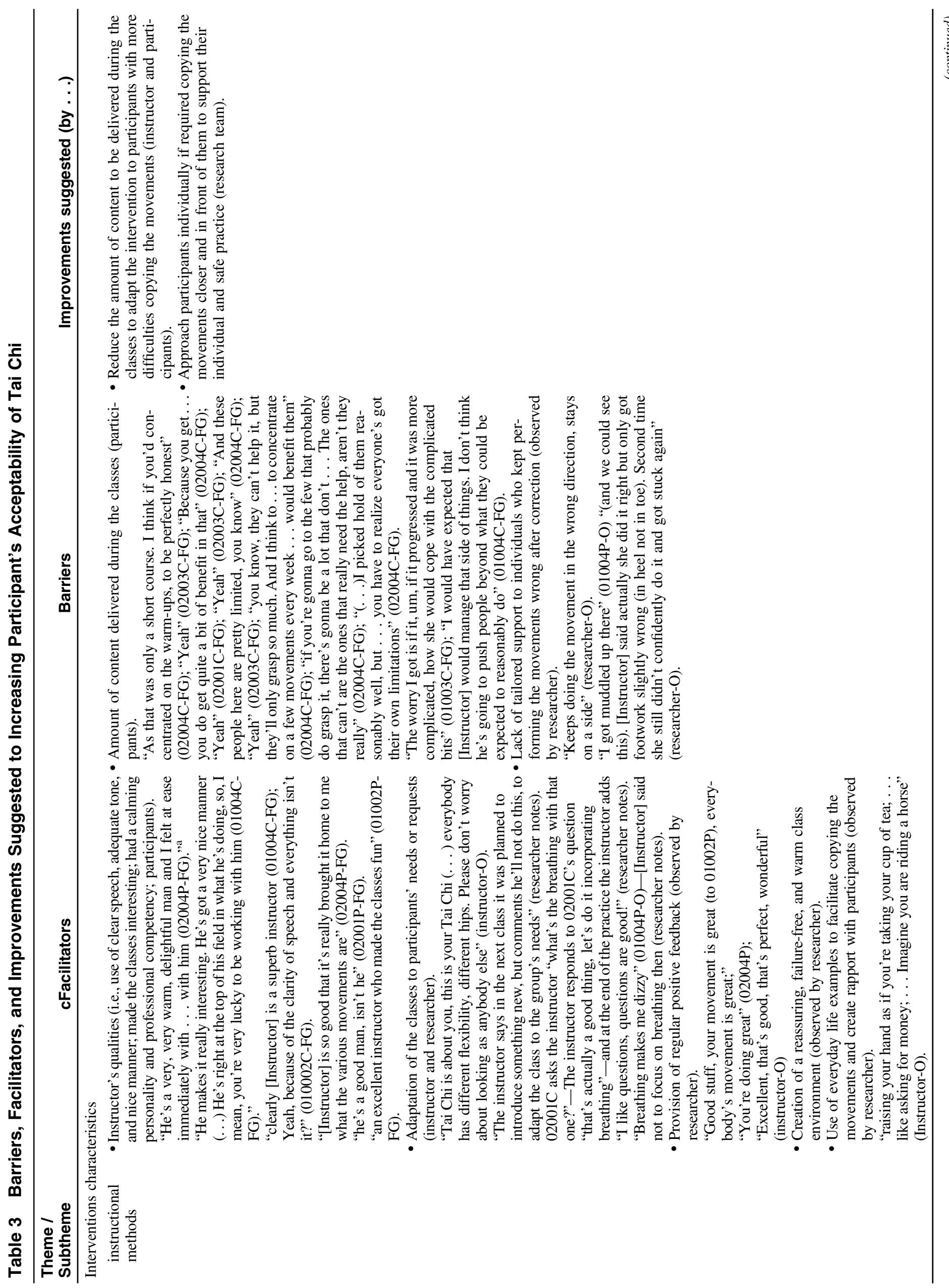




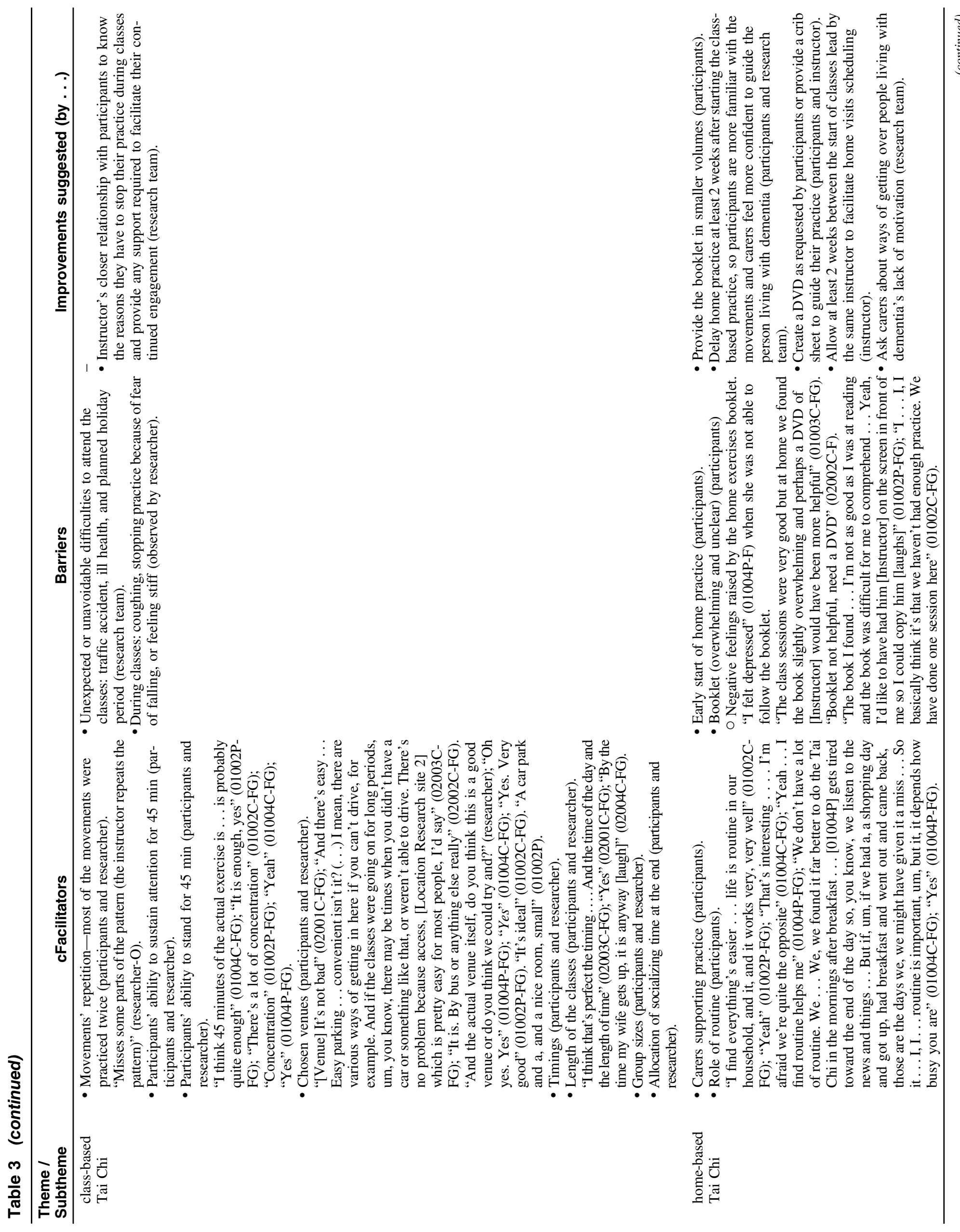




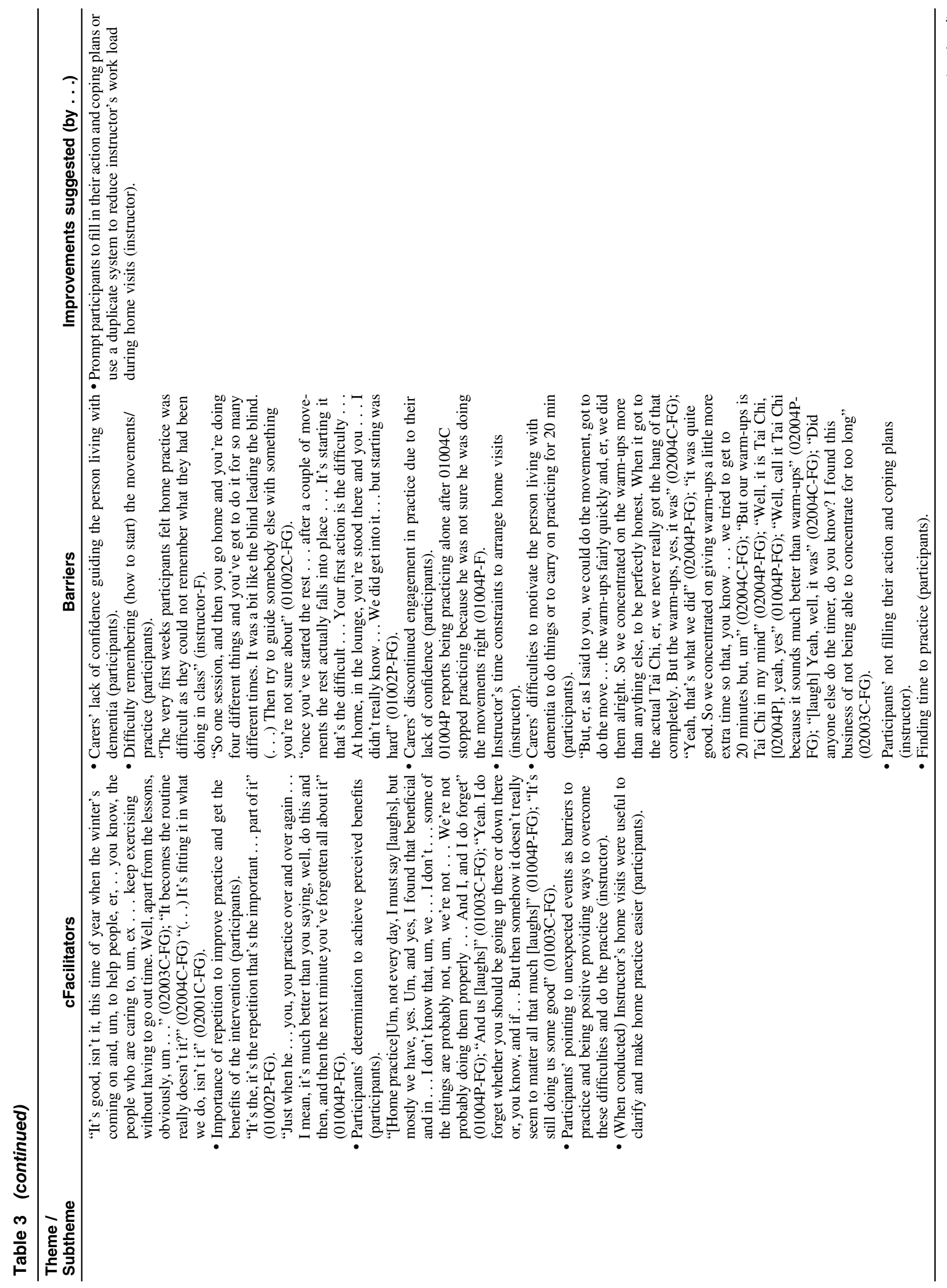




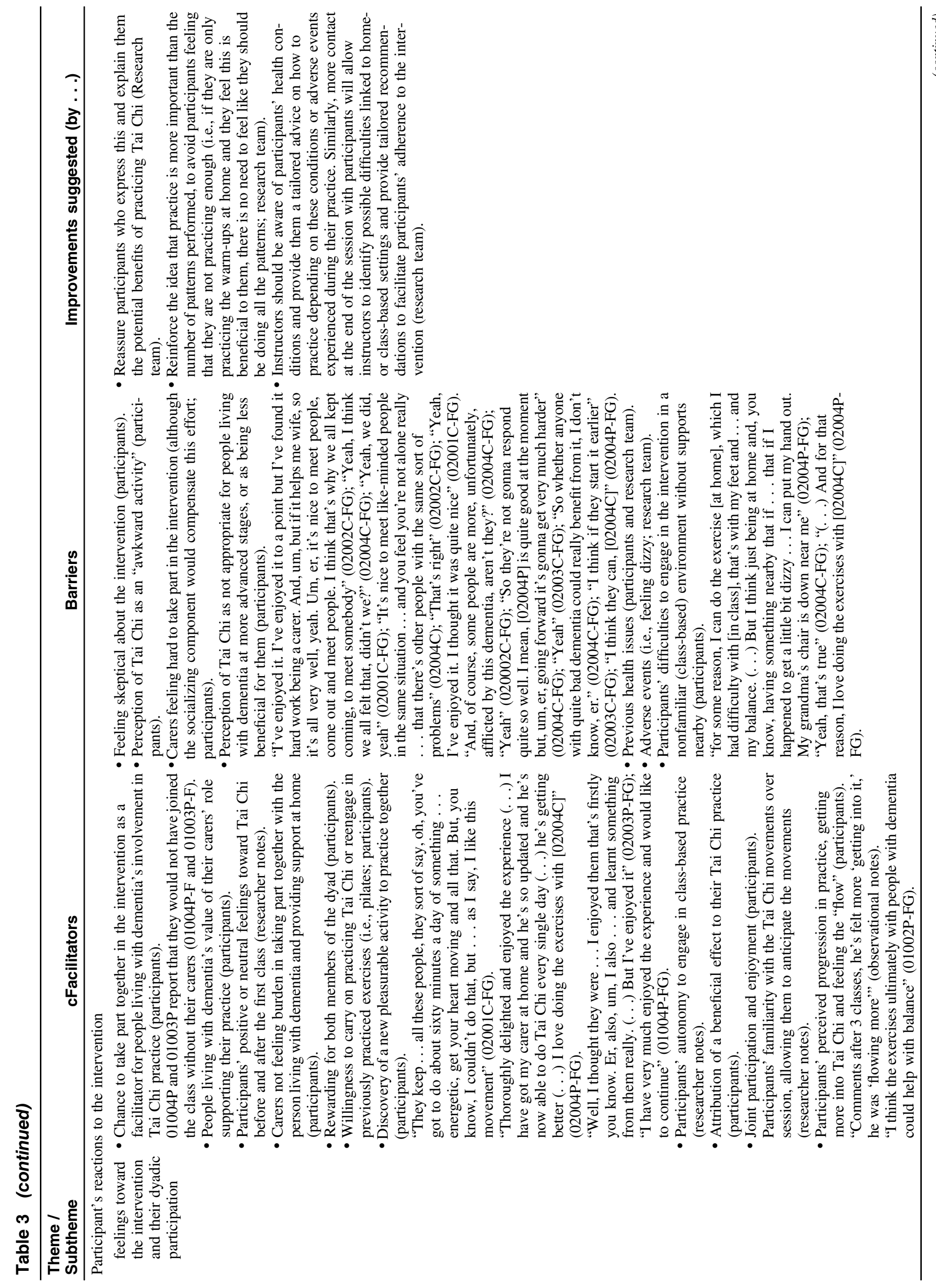




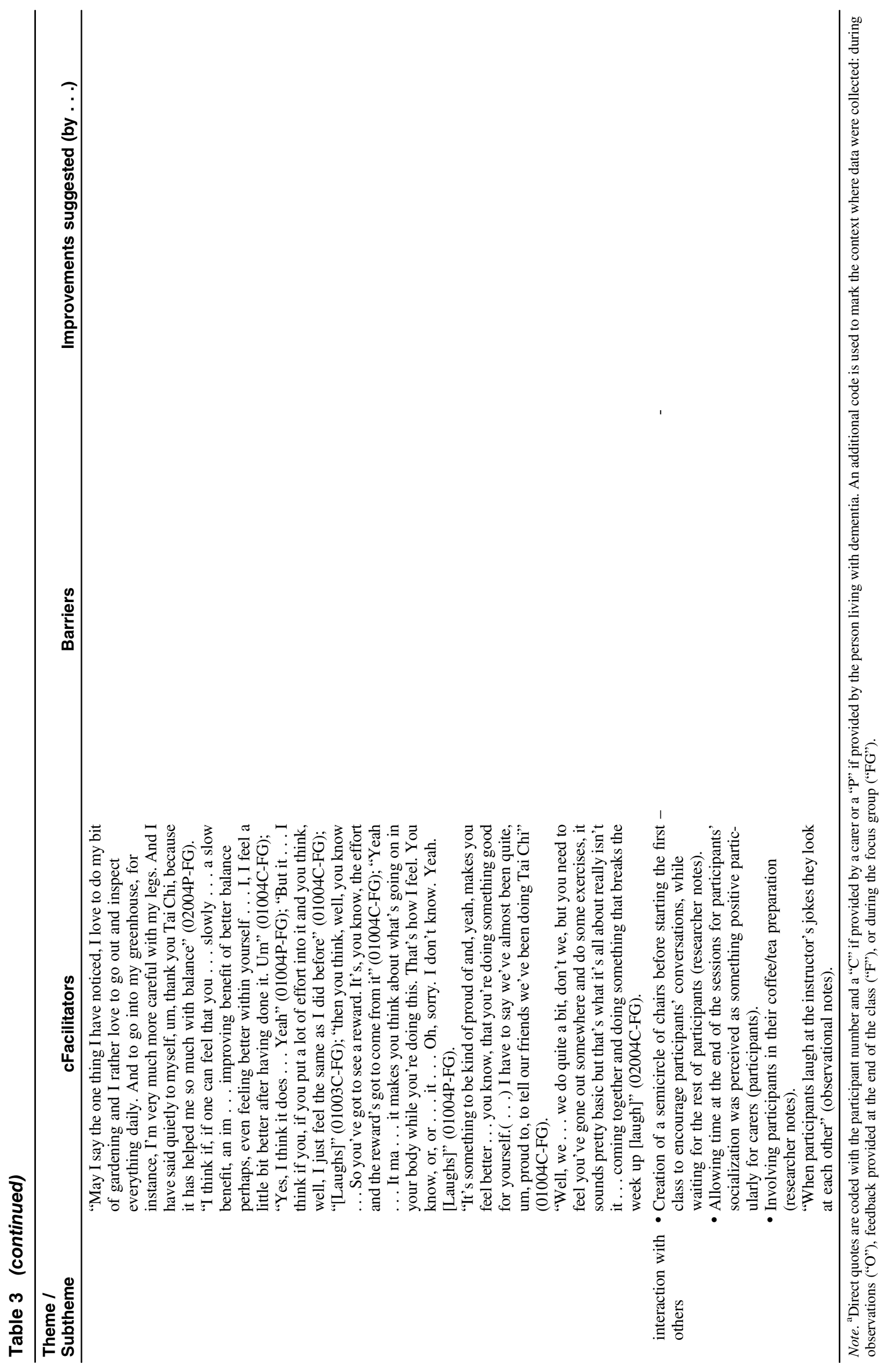


classes to encourage participants' engagement in the activity and reassured the participants when they verbalized difficulties while doing Tai Chi at home or during classes. Sometimes, this positive feedback was given when some participants were struggling to perform the movements or doing them incorrectly. This approach was chosen by the instructor for this study to facilitate their engagement and was positively perceived by one of the carers during a focus group:

when he's doing the exercises, he says, oh, that's good, yes, that's right, you're doing it right there, but . . . you know they're not really but . . . he's just encouraging (02001C-FG).

However, corrections were mostly made as a general comment not directed to individual participants (i.e., "golden rule: your knees very slightly bent go forward and your heels stay in the ground" [O]), unless participants had expressed a particular difficulty in performing a movement. The instructor reinforced participants' home practice by providing positive feedback (i.e., "I can see some of you have been practicing" [O]).

The instructor adapted the intervention to participants' needs and responded to their requests (i.e., introducing breathing while practicing one movement, as requested by a carer during the class) to make the intervention accessible for both people living with dementia and their carers. He emphasized the need of participants to focus only on their own performance.

Class- and home-based Tai Chi practice. Occasionally, participants performed better when attempting a move for the second time during a class. However, more frequently participants (mostly people living with dementia) carried on practicing the movement in the opposite direction, bending too much forward or pausing their engagement in the activity. During the first class, participants living with dementia stood closer to their carers; however, in the classes that followed three of the carers in Site 2 practiced in front, leaving the person living with dementia to work individually behind them.

At home, eight of ten dyads reported that they had managed to do some practice. Dyads who did not report any practice were the one dyad who withdrew after the first class and another dyad who attended all the classes but was not able to practice due to an unexpected lack of time.

Two carers verbalized their difficulties motivating the person living with dementia to do things, which had an impact on their home practice, meaning that they did not manage to do any practice or not more than 20 min during 1 week. However, only one participant living with dementia struggling to practice at home had experienced difficulties following the classes, instead focused on doing the warm-ups ("you do get quite a bit of benefit in that" [02004C-FG], "But our warm-ups is Tai Chi in my mind" [02004P-FG]).

The lack of guidance and confidence when practicing at home was the main issue raised by participant dyads. Particularly, carers felt like the "blind leading the blind," which led one of the carers to stop practicing at home, while the person living with dementia carried on alone, convinced that any practice would be positive for her. The booklet in all the cases was perceived as not useful, unclear, and with inconsistent (picture description) instructions, which failed to show the progression of the movements (see Table 3 for example quotes).

\section{Participants' Reactions to the Intervention}

Subthemes contained by this overarching theme relate to the way participants responded to the intervention in terms of their: (a) feelings toward the intervention and their dyadic participation and (b) interaction with others (see Table 3).

Feelings toward the intervention and their dyadic participation. Before starting the classes and after the first class, half the dyads were particularly passionate and enthusiastic about the opportunity of taking part in Tai Chi, whereas the rest were more neutral in their behaviors and expressions. In general, participants had neutral and positive feelings toward the intervention ("a good addition to my life" [02005P-F]). All participants shared their enjoyment of the intervention and the socializing component, when providing feedback (see Table 3 for example quotes). However, only occasionally they verbalized this satisfaction during the class (i.e., "I like it!" [01002P-O]). In Site 2, participants expressed their content nonverbally at the end of the class by clapping the instructor.

Tai Chi was perceived as a different activity that participants were not familiar with, however, this had no impact on participants' enjoyment and engagement in the activity ("It's strange from another tasters that I went to, but I like it" [02003P-FG]). Tai Chi is an activity that carers see themselves doing with their partners to improve or maintain their physical condition unlike other types of exercise and both enjoy doing.

Carers did not find their joint participation to be a burden. Only one expressed it had been hard as a carer, although he would keep going for the person living with dementia and the possibility of meeting with other carers. Similarly, only one participant living with dementia seemed to react negatively toward the intervention, feeling "distressed before going" [02006C-F] to the sessions as reported by the carer.

During the classes, all participants were focused in the session, looking at the instructor and copying his movements. Three participants expressed that they had experienced difficulties following the classes after the first session, one due to their fear of falling, and two because they struggled during sessions when copying more complicated patterns. However, it was clearly observed that an additional participant who did not report any difficulties also struggled copying some of the movements. One of the participants living with dementia, on the contrary, according to the instructor and first author's observations got more into the intervention and was able to follow the class without verbal prompting from the carer. Carers engaged in the intervention reported no difficulties in copying the movements during the classes. In general, participants appear to enhance their perceptions of competence during sessions and with practice, feelings of the "flow," and getting other benefits of the intervention. Participants' progress was already noticeable in the second class when half of the participants living with dementia and carers anticipated the movements taught by the instructor. Finally, three nonserious and nonsevere, and expected adverse events experienced by participants were rated as definitely/probably/possibly related to the intervention: dizziness - reported by two participants living with dementia and pain-reported by a carer and attributed to previous conditions, which did not impact on their willingness to carry on practicing Tai Chi.

The most important facilitators of participants' engagement in the intervention were the benefits perceived by both members of the dyad after taking part in the intervention: (a) relaxation; (b) exercise for health benefits-increasing activity levels, keeping muscle supple; (c) body awareness-"it makes you think about what's going on in your body, while you're doing this" (01004P-FG); (d) brain stimulation; and (e) balance improvement. Taking part in the intervention was perceived as a source of pride in itself. 
Interactions with others. During the classes, most of the interactions were initiated by the instructor as he was the one leading the session. However, participants reacted to the instructor's comments frequently with smiles and laughs. In both sites only occasionally there was an interaction between members of the same dyad, for instance, in the form of nonverbal interactions expressing mutual understanding. When the carers started a verbal interaction this was always in a soft and comfortable way to ensure the person living with dementia was all right or to support the instructions provided by the instructor. At the end of the class, participants were able to engage in informal conversation with other dyads and the instructor

\section{Discussion}

The aim of this study was to understand what is influencing the acceptability of Tai Chi among people living with dementia and their carers and how this could be enhanced. Findings suggest that Tai Chi is perceived by people living with dementia of mildmoderate severity and their carers as an enjoyable activity that they can readily carry out together. Carers play a key role in supporting people living with dementia's involvement in the classes and facilitating home practice, therefore content and supporting materials must be carefully adapted so that both members feel comfortable when practicing at home. Once incorporated in their routines, Tai Chi could be an enjoyable and mutually beneficial activity.

Caution is required in supporting the acceptability of Tai Chi as a falls prevention intervention, as recruitment was challenging. An important reason for this is that eligible participants felt that they were not at risk of falls (Hawley-Hague et al., 2016) and that a falls prevention intervention was not for them. This has been a common problem in that participants rate exercise intervention designed to reduce falls as important for other people (Haines, Day, Hill, Clemson, \& Finch, 2014). In this study, there were also participants who did not feel they were at risk of falls, which is consistent with the findings of another study with older participants (Yardley et al., 2006). For this reason, in the RCT phase of the TACIT trial we have changed our strategy to take the emphasis away from falls to general health and well-being.

\section{Class-Based Practice}

The intervention was widely accepted by participants who particularly adhered to the class-based component. Consistent with previous exercise research, the qualities of the instructor (HawleyHague et al., 2016), the creation of a warm and failure-free environment (Barnes et al., 2015), and the socializing component (Wu et al., 2015) have been positively valued by participants and influenced their adherence to the study.

Researchers observed that participants living with dementia at times struggled to copy the instructor; however, these participants only reported their enjoyment of Tai Chi. One reason for this might be that they felt able to do the Tai Chi well enough and so report that they found the experience enjoyable. This could be partially supported by previous research suggesting that participants' enjoyment of the intervention could be critical for their sustained participation in falls prevention interventions (McPhate et al., 2016). Previous studies have also found apathy in participants with lack of insight to their dementia symptoms (Aalten et al., 2006). This could explain a lack of awareness about their performance during the classes and their tendency not to communicate their difficulties. However, participants' enjoyment of the socializing component could have impacted more positively on their acceptability of the intervention, as the satisfaction of the social need seemed to be crucial for people living with dementia (Maki, Amari, Yamaguchi, Nakaaki, \& Yamaguchi, 2012).

Low sense of efficacy performing the movements perceived by the carer or the person living with dementia could have an impact on participants' willingness to carry on taking part in the intervention. Both dyads who expressed this lack of competence ended up not willing (or not being able, due to health issues) to attend further sessions. In light of these results, tailored support from the instructor (Chong et al., 2014; Day, Trotter, Donaldson, Hill, \& Finch, 2016; Pitkälä et al., 2013) in becoming aware of these perceptions could facilitate their adherence to the exercise intervention. However, having successful experiences and verbal encouragement from the instructor could have enhanced most participants' efficacy beliefs (Bandura, 1977), which in turn have been shown to be a predictor of perseverance and adherence (Alharbi et al., 2016).

\section{Home-Based Practice}

The home-based component was generally well perceived by participants who included Tai Chi practice in their routines. However, their acceptability was challenged due to their difficulties remembering the Tai Chi movements at home, which was not improved by the use of the home-exercise booklet. Such difficulties could have potentially impacted on participants' adherence to the home-based component. Our results expand on previous research findings suggesting the use of memory aids such as exercise booklets with images and explanations to support home practice (Connell \& Janevic, 2009; Logghe et al., 2011; Logsdon, McCurry, Pike, \& Teri, 2009; Prick et al., 2014; Suttanon et al., 2013) and highlight the need for additional support so participants can perceive movements' progression.

Difficulties to sustain attention have not been previously identified in exercise interventions for people living with dementia (Dal Bello-Haas et al., 2014; Prick et al., 2014). However, in this study, difficulties reported by two carers trying to get the attention of the person living with dementia for $20 \mathrm{~min}$ in one bout could be motivated by the home environment and the level of confidence of the carer supporting this practice. Previous research suggested that instructions provided by the instructor could have more impact on the person living with dementia than the ones offered by the carer (Prick et al., 2014), which could be influenced by the instructional methods and qualities of the instructor.

\section{Dyadic Approach}

In this study, the use of a dyadic approach was accepted by both people living with dementia and their carers. This finding concurs with previous studies where a dyadic approach had been used to facilitate people living with dementia's adherence to exercise interventions (Teri et al., 2003; Yao et al., 2012). Results from this study suggest that this dyadic approach could not only facilitate their adherence to the intervention, but also enable people living with dementia's inclusion in these interventions. In the same way, feedback from carers reinforces the use of this dyadic approach in the context of dementia as it gives them the opportunity to discover enjoyable activities that could evolve to shared interests. These would be of particular relevance when these common activities could be helpful for carers (to experience their role more positively) and the person living with dementia (to feel competent and empowered; DiLauro, Pereira, Carr, Chiu, \& Wesson, 2015; Lamotte, Shah, Lazarov, \& Corcos, 2016). Another strength of this dyadic approach highlighted by carers is that both, they themselves and the 
person living with dementia, benefit from taking part in Tai Chi. This perceived benefit could potentially mean carers are willing to carry on practicing after their involvement in the study, which would also be of benefit for the person living with dementia (Lamotte et al., 2016). In contrast to some reports in the literature (Wesson et al., 2013; Woods et al., 2016), carers did not perceive their involvement in this study as a burden.

\section{Strengths and Limitations}

Our results describe for the first time how people living with dementia and their carers respond to a Tai Chi exercise intervention. This study is the first of its kind to use qualitative methods to understand how appropriate a Tai Chi intervention is for people living with dementia and their carers. The use of a dyadic approach to gather the views of participants living with dementia and their carers has enabled carers to support the researcher by rephrasing questions and inviting the person living with dementia to provide their views during the focus groups, as found in previous research (Nyman, Innes, \& Heward, 2016; Prick et al., 2014) and in the TACIT trial public and patient involvement advisory group.

This study has a number of limitations. First, the quality of the observations may have been impacted by the fact that the Tai Chi classes were not video recorded (as the instructor did not consent for him or participants to be recorded during classes). The researcher may have missed some participants' reactions, while they were taking notes on different participants. Second, feedback from the two dyads who withdrew from the intervention was limited because one did not agree to take part in the final focus group and the other dyad was not feeling well after their holiday period. An interview with the dyad that withdrew during the first class could have provided more insight into ways of facilitating their acceptability of the intervention. Third, time to collect participants' views at the end of the class was also limited; however, capturing how people feel in that specific moment (after practicing Tai Chi) could be particularly relevant in the context of dementia as recall could be facilitated by interviewing participants in their natural environment where they were taking part in the activity (Nygård, 2006). Finally, during one of the focus group participants living with dementia could have felt uncomfortable by hearing their carers commenting they are not always able to provide accurate responses. Although people living with dementia did not seem to respond verbally or nonverbally to this, this could have silenced their voices.

\section{Practical Implications}

This study highlights three main aspects, which should be considered in designing future exercise programs for people with dementia. First, the use of a dyadic approach in exercise interventions could be beneficial for both the person living with dementia and the carer at an individual level, but also facilitate their uptake of the intervention, as this would provide them with a potential common interest. Second, the combination of class- and home-based practice could be advantageous to reinforce participants' social support networks as well as strengthen dyadic relationships and facilitate the acceptability of the intervention by feeling an increased competence. Third, instructors' awareness of dementia and adapted instructional methods in class and support materials at home facilitate participants' acceptability of the classes. For this reason, it must be considered that booklets with images and descriptions might be insufficient for people living with dementia and their carers when facing unfamiliar movements such as those of Tai Chi. In this case, simple, clear, and when possible, dynamic prompts (i.e., DVD) are advised.

\section{Future Research}

Future research investigating the acceptability of Tai Chi should consider the inclusion of participants from different ethnic backgrounds and with different relationships with the person living with dementia (other than spouse). In this study, informal carers were sought to be recruited independently from their relationship with the person living with dementia. However, only one dyad was not formed by a couple and in all cases the person living with dementia was living with the informal carer, which could have influenced their acceptability of the intervention and particularly their availability to take part in home-based practice. Similarly, the impact of the size of the group on dyads acceptability was only explored in two small groups, which could be less cost effective in community settings. The acceptability of larger groups formed by dyads rests unexplored in the context of exercise interventions for people living with dementia and their informal carers.

\section{Conclusion}

In summary, this novel study contributes to our understanding of the experiences, needs, and preferences of people living with dementia taking part in exercise interventions with their carers. Intervention's characteristics and participants' reactions to the intervention might impact on their acceptability of exercise interventions. A series of improvements have been suggested by participants, instructor, and the research team to facilitate the engagement of people living with dementia with different levels of performance (i.e., reducing the amount of content to be delivered) and support home practice (i.e., adjusting materials).

\section{Acknowledgments}

The TACIT trial and PhD studentship awarded to Y. Barrado-Martín are funded by a National Institute for Health Research (NIHR) career development fellowship awarded to Dr. S. R. Nyman, Bournemouth University. This paper presents independent research funded by the NIHR's career development fellowship program. The views expressed are those of the authors and not necessarily those of the NHS, the NIHR, or the Department of Health. The authors acknowledge senior instructor Robert Joyce, Elemental Tai Chi, who designed and delivered the Tai Chi course for this study. The authors acknowledge the advice received from Dr. Shanti Shanker in regard to cognitive testing, Dr. Jonathan Williams in regard to objective measurement of static and dynamic balance, and our public and patient involvement group on our approach to recruitment and data collection. The authors thank the Alzheimer's society for their assistance with publicizing the study and the two main recruitment sites: Memory Assessment Research Centre, Southern Health NHS Foundation Trust (principal investigator: Brady McFarlane) and Memory Assessment Service, Dorset HealthCare University NHS Foundation Trust (principal investigator: Kathy Sheret). The authors acknowledge the Southern Health NHS Foundation Trust for sponsorship of the pilot intervention phase (for contact details, please see ClinicalTrials.Gov registration). The sponsor's responsibilities are as defined in the Research Governance Framework for Health and Social Care (second edition, 2005).

\section{References}

Aalten, P., van Valen, E., de Vugt, M.E., Lousberg, R., Jolles, J., \& Verhey, F.R.J. (2006). Awareness and behavioral problems in dementia patients: A prospective study. International Psychogeriatrics, 
18(1), 3-17. PubMed ID: 16388704 doi:10.1017/S1041610 205002772

Abraha, I., Rimland, J.M., Trotta, F.M. , Dell'Aquila, G., Cruz-Jentoft, A., Petrovic, M., . . . Cherubini, A. (2017). Systematic review of systematic reviews of non-pharmacological interventions to treat behavioural disturbances in older patients with dementia. The SENATOR-OnTop series. BMJ Open, 7, e012759. doi:10.1136/bmjopen-2016-012759

Alharbi, M., Gallagher, R., Neubeck, L., Bauman, A., Prebill, G., Kirkness, A., \& Randall, S. (2016). Exercise barriers and the relationship to self-efficacy for exercise over 12 months of a lifestyle-change program for people with heart disease and/or diabetes. European Journal of Cardiovascular Nursing, 16(4), 309-317. PubMed ID: 27562115 doi:10.1177/1474515116666475

Alzheimer's Disease International. (2015). Dementia statistics. Retrieved from http://www.alz.co.uk/research/statistics

Alzheimer's Research UK. (2015). Dementia in the family: The impact on carers. Retrieved from https://www.alzheimersresearchuk.org/wpcontent/uploads/2015/12/Dementia-in-the-Family-The-impact-oncarers.pdf

Alzheimer's Society. (2015). Factsheet 458LP: The progression of Alzheimer's disease and other dementias. Retrieved from https://www. alzheimers.org.uk/site/scripts/download_info.php?fileID=1772

Austin, Z., \& Sutton, J. (2014). Qualitative research: Getting started. The Canadian Journal of Hospital Pharmacy, 67(6), 436-440. PubMed ID: 25548401 doi:10.4212/cjhp.v67i6.1406

Bandura, A. (1977). Self-efficacy: Toward a unifying theory of behavioral change. Psychological Review, 84(2), 191-215. PubMed ID: 847061 doi:10.1037/0033-295X.84.2.191

Barnes, D.E., Mehling, W., Wu, E., Beristianos, M., Yaffe, K., Skultety, K., \& Chesney, M.A. (2015). Preventing loss of independence through exercise (PLIÉ): A pilot clinical trial in older adults with dementia. PLoS ONE, 10(2), e0113367. PubMed ID: 25671576 doi:10.1371/journal.pone.0113367

Braun, V., \& Clarke, V. (2013). Successful qualitative research: A practical guide for beginners. London, UK: Sage.

Burgener, S.C., Yang, Y., Gilbert, R., \& Marsh-Yant, S. (2008). The effects of a multimodal intervention on outcomes of persons with early-stage dementia. American Journal of Alzheimer's Disease \& Other Dementias, 23(4), 382-394. PubMed ID: 30136290 doi:10. $1177 / 1533317508317527$

Burton, E., Cavalheri, V., Adams, R., Browne, C.O., Bovery-Spencer, P., Fenton, A.M., . . . Hill, K.D. (2015). Effectiveness of exercise programs to reduce falls in older people with dementia living in the community: A systematic review and meta-analysis. Clinical Interventions in Aging, 10, 421-434. PubMed ID: 25709416 doi:10.2147/CIA.S71691

Cameron, I.D., Gillespie, L.D., Robertson, M.C., Murray, G.R., Hill, K.D., Cumming, R.G., \& Kerse, N. (2012). Interventions for preventing falls in older people in care facilities and hospitals. Cochrane Database of Systematic Reviews, (12), CD005465. doi:10.1002/14651858. CD005465.pub3

Chase, J.-A.D. (2015). Interventions to increase physical activity among older adults: A meta-analysis. Gerontologist, 55(4), 706-718. PubMed ID: 25298530 doi:10.1093/geront/gnu090

Chew, J., Chong, M.S., Fong, Y.L., \& Tay, L. (2015). Outcomes of a multimodal cognitive and physical rehabilitation program for persons with mild dementia and their caregivers: A goal-oriented approach. Clinical Interventions in Aging, 10, 1687-1694. PubMed ID: 26543358 doi:10.2147/CIA.S93914

Chong, T.W.H., Doyle, C.J., Cyarto, E.V., Cox, K.L., Ellis, K.A., Ames, D., \& Lautenschlager, N.T. (2014). Physical activity program preferences and perspectives of older adults with and without cognitive impairment. Asia-Pacific Psychiatry, 6(2), 179-190. PubMed ID: 23857923 doi:10.1111/appy.12015

Connell, C.M., \& Janevic, M.R. (2009). Effects of a telephone-based exercise intervention for dementia caregiving wives: A randomized controlled trial. Journal of Applied Gerontology, 28(2), 171-194. PubMed ID: 21709757 doi:10.1177/0733464808326951

Dal Bello-Haas, V.P.M., O'Connell, M.E., Morgan, D.G., \& Crossley, M. (2014). Lessons learned: Feasibility and acceptability of a telehealthdelivered exercise intervention for rural-dwelling individuals with dementia and their caregivers. Rural and Remote Health, 14(3), 2715. Retrieved from http://www.rrh.org.au/publishedarticles/article_ print_2715.pdf PubMed ID: 25081991

Day, L., Trotter, M.J., Donaldson, A., Hill, K.D., \& Finch, C.F. (2016). Key factors influencing implementation of falls prevention exercise programs in the community. Journal of Aging and Physical Activity, 24(1), 45-52. PubMed ID: 25838262 doi:10.1123/japa. 2014-0143

Deci, E.L., \& Ryan, R.M. (2000). The "what" and "why" of goal pursuits: Human needs and the self-determination of behavior. Psychological Inquiry, 11(4), 227-268. doi:10.1207/S15327965PLI1104_01

Dewing, J. (2008). Process consent and research with older persons living with dementia. Research Ethics Review, 4(2), 59-64. doi:10.1177/ 174701610800400205

DiLauro, M., Pereira, A., Carr, J., Chiu, M., \& Wesson, V. (2015). Spousal caregivers and persons with dementia: Increasing participation in shared leisure activities among hospital-based dementia support program participants. Dementia, 16(1), 9-28. doi:10.1177/ 1471301215570680

Drabble, S.J., O'Cathain, A., Thomas, K.J., Rudolph, A., \& Hewison, J. (2014). Describing qualitative research undertaken with randomised controlled trials in grant proposals: A documentary analysis. BMC Medical Research Methodology, 14, 24. PubMed ID: 24533771 doi:10.1186/1471-2288-14-24

Fetherston, C.M., \& Wei, L. (2011). The benefits of tai chi as a self management strategy to improve health in people with chronic conditions. Journal of Nursing \& Healthcare of Chronic Illnesses, 3(3), 155-164. doi:10.1111/j.1752-9824.2011.01089.x

Fleiner, T., Dauth, H., Gersie, M., Zijlstra, W., \& Haussermann, P. (2017). Structured physical exercise improves neuropsychiatric symptoms in acute dementia care: A hospital-based RCT. Alzheimer's Research \& Therapy, 9, 1-9. PubMed ID: 30165077 doi:10.1186/s13195-0160227-5

Frederiksen, K.S., Sobol, N., Beyer, N., Hasselbalch, S., \& Waldemar, G. (2014). Moderate-to-high intensity aerobic exercise in patients with mild to moderate Alzheimer's disease: A pilot study. International Journal of Geriatric Psychiatry, 29(12), 1242-1248. PubMed ID: 24733599 doi:10.1002/gps.4096

Gillespie, L.D., Robertson, M.C., Gillespie, W.J., Sherrington, C., Gates, S., Clemson, L.M., \& Lamb, S.E. (2012). Interventions for preventing falls in older people living in the community. Cochrane Database of Systematic Reviews, (9), CD007146. doi:10.1002/14651858. CD007146.pub3

Haines, T.P., Day, L., Hill, K.D., Clemson, L., \& Finch, C. (2014). "Better for others than for me:" A belief that should shape our efforts to promote participation in falls prevention strategies. Archives of Gerontology and Geriatrics, 59(1), 136-144. PubMed ID: 24745812 doi:10.1016/j.archger.2014.03.003

Hamilton, S., Ramsay, E., Webster, L., Payne, N.L., Taylor, M.E., Close, J.C.T., . . . Brodaty, H. (2017). A home-based, carer-enhanced exercise program improves balance and falls efficacy in community-dwelling older people with dementia. International Psychogeriatrics, 29(1), 81-91. doi:10.1017/S1041610216001629 
Hawley-Hague, H., Horne, M., Skelton, D.A., \& Todd, C. (2016). Older adults' uptake and adherence to exercise classes: Instructors' perspectives. Journal of Aging and Physical Activity, 24(1), 119-128. PubMed ID: 26214265 doi:10.1123/japa.2014-0108

Hsieh, S., McGrory, S., Leslie, F., Dawson, K., Ahmed, S., Butler, C.R., . . . Hodges, J.R. (2015). The mini-Addenbrooke's cognitive examination: A new assessment tool for dementia. Dementia and Geriatric Cognitive Disorders, 39, 1-11. PubMed ID: 25227877 doi:10.1159/000366040

Judson, M.A. (2015). The clinical features of sarcoidosis: A comprehensive review. Clinical Reviews in Allergy \& Immunology, 49(1), 63-78. PubMed ID: 25274450 doi:10.1007/s12016-014-8450-y

Kinney, J.M., \& Rentz, C.A. (2005). Observed well-being among individuals with dementia: Memories in the Making, an art program, versus other structured activity. American Journal of Alzheimer's Disease and Other Dementias, 20(4), 220-227. PubMed ID: 30136290 doi:10.1177/153331750502000406

Lamotte, G., Shah, R.C., Lazarov, O., \& Corcos, D.M. (2016). Exercise training for persons with Alzheimer's disease and caregivers: A review of dyadic exercise interventions. Journal of Motor Behavior, 1-13. doi:10.1080/00222895.2016.1241739

Laver, K., Dyer, S., Whitehead, C., Clemson, L., \& Crotty, M. (2016). Interventions to delay functional decline in people with dementia: A systematic review of systematic reviews. BMJ Open, 6(4), e010767. doi:10.1136/bmjopen-2015-010767

Logghe, I.H.J., Verhagen, A.P., Rademaker, A.C.H.J., Zeeuwe, P.E.M., Bierma-Zeinstra, S.M.A., Van Rossum, E., . . Koes, B.W. (2011). Explaining the ineffectiveness of a Tai Chi fall prevention training for community-living older people: A process evaluation alongside a randomized clinical trial (RCT). Archives of Gerontology and Geriatrics, 52(3), 357-362. PubMed ID: 20965096 doi:10.1016/j. archger.2010.05.013

Logsdon, R.G., McCurry, S.M., Pike, K.C., \& Teri, L. (2009). Making physical activity accessible to older adults with memory loss: A feasibility study. The Gerontologist, 49(Suppl. 1), S94-S99. doi:10. 1093/geront/gnp082

Logsdon, R.G., McCurry, S.M., \& Teri, L. (2005).A home health care approach to exercise for persons with Alzheimer's disease. Care Management Journals, 6(2), 90-97. Retrieved from https://www. ncbi.nlm.nih.gov/pubmed/16544870

Maki, Y., Amari, M., Yamaguchi, T., Nakaaki, S., \& Yamaguchi, H. (2012). Anosognosia: Patients' distress and self-awareness of deficits in Alzheimer's disease. American Journal of Alzheimer's Disease and Other Dementias, 27(5), 339-345. PubMed ID: 30136290 doi:10.1177/1533317512452039

McPhate, L., Simek, E.M., Haines, T.P., Hill, K.D., Finch, C.F., \& Day, L. (2016). "Are your clients having fun?" The implications of respondents' preferences for the delivery of group exercise programs for falls prevention. Journal of Aging and Physical Activity, 24(1), 129138. PubMed ID: 26215164 doi:10.1123/japa.2014-0168

National Health Service. (2017). Diverticular disease and diverticulitis. Retrieved from http://www.nhs.uk/conditions/Diverticular-diseaseand-diverticulitis/Pages/Introduction.aspx

National Health Service. (2016). Fibromyalgia. Retrieved from http:// www.nhs.uk/Conditions/Fibromyalgia/Pages/Introduction.aspx

National Institute for Health and Care Excellence. (2013). Falls in older people: Assessing risk and prevention. Retrieved from https://www. nice.org.uk/guidance/ph49/resources/behaviour-change-individualapproaches-pdf-1996366337989

National Institute for Health and Care Excellence. (2014). Behaviour change: Individual approaches. Retrieved from https://www. nice.org.uk/guidance/ph49/resources/behaviour-change-individualapproaches-pdf-1996366337989
Nygård, L. (2006). How can we get access to the experiences of people with dementia? Suggestions and reflections. Scandinavian Journal of Occupational Therapy, 13(2), 101-112. doi:10.1080/11038120 600723190

Nyman, S.R., Innes, A., \& Heward, M. (2016). Social care and support needs of community-dwelling people with dementia and concurrent visual impairment. Aging and Mental Health, 21(9), 961-967. PubMed ID: 27215277 doi:10.1080/13607863.2016.1186151

Nyman, S.R., \& Skelton, D. (2017). The case for Tai Chi in the repertoire of strategies to prevent falls among older people. Perspectives in Public Health, 137(2), 85-86. doi:10.1177/1757913916685642

O'Cathain, A., Thomas, K.J., Drabble, S.J., Rudolph, A., \& Hewison, J. (2013). What can qualitative research do for randomised controlled trials? A systematic mapping review. BMJ Open, 3(6), e002889. doi:10.1136/bmjopen-2013-002889

Öhman, H., Savikko, N., Strandberg, T.E., Kautiainen, H., Raivio, M.M., Laakkonen, M.-L., . . . Pitkälä, K.H. (2016). Effects of exercise on cognition: The Finnish Alzheimer Disease Exercise Trial: A randomized, controlled trial. Journal of the American Geriatrics Society, 64(4), 731-738. PubMed ID: 27037872 doi:10.1111/jgs. 14059

Öhman, H., Savikko, N., Strandberg, T.E., \& Pitkälä, K.H. (2014). Effect of physical exercise on cognitive performance in older adults with mild cognitive impairment or dementia: A systematic review. Dementia and Geriatric Cognitive Disorders, 38(5-6), 347-365. doi:10. $1159 / 000365388$

Patton, M.Q. (2013). Qualitative research and evaluation methods (4th ed.). Los Angeles, CA: Sage.

Pitkälä, K.H., Pöysti, M.M., Laakkonen, M.-L., Tilvis, R.S., Savikko, N., Kautiainen, H., \& Strandberg, T.E. (2013). Effects of the Finnish Alzheimer Disease Exercise Trial (FINALEX): A randomized controlled trial. JAMA Internal Medicine, 173(10), 894-901. doi:10. 1001/jamainternmed.2013.359

Prick, A.E., de Lange, J., van 't Leven, N., \& Pot, A.M. (2014). Process evaluation of a multicomponent dyadic intervention study with exercise and support for people with dementia and their family caregivers. Trials, 15(1), 401-414. doi:10.1186/17456215-15-401

QSR International Pty Ltd. (2015). NVivo qualitative data analysis software (Version 11).

Rao, A.K., Chou, A., Bursley, B., Smulofsky, J., \& Jezequel, J. (2014). Systematic review of the effects of exercise on activities of daily living in people with Alzheimer's disease. American Journal of Occupational Therapy, 68(1), 50-56. PubMed ID: 24367955 doi:10.5014/ajot.2014.009035

Saldaña, J. (2016). The coding manual for qualitative researchers (3rd ed.). London, UK: Sage.

Saravanakumar, P., Higgins, I.J., Van Der Riet, P.J., Marquez, J., \& Sibbritt, D. (2014). The influence of Tai Chi and yoga on balance and falls in a residential care setting: A randomised controlled trial. Contemporary Nurse, 48(1), 76-87. PubMed ID: 25410198 doi:10.1080/10376178.2014.11081929

Shaw, F.E. (2003). Falls in older people with dementia. Geriatrics and Aging, 6(7), 37-40. Retrieved from https://www.healthplexus.net/ files/content/2003/August/0607dementiafall.pdf

Shelat, A.M. (2016). Neuralgia. Retrieved from https://medlineplus.gov/ ency/article/001407.htm

Sherrington, C., Whitney, J.C., Lord, S.R., Herbert, R.D., Cumming, R.G., \& Close, J.C. (2008). Effective exercise for the prevention of falls: A systematic review and meta-analysis. Journal of the American Geriatrics Society, 56(12), 2234-2243. PubMed ID: 19093923 doi:10. $1111 /$ j.1532-5415.2008.02014.x 
Strookappe, B., Swigris, J., De Vries, J., Elfferich, M., Knevel, T., \& Drent, M. (2015). Benefits of physical training in sarcoidosis. Lung, 193(5), 701-708. PubMed ID: 26286208 doi:10.1007/s00408-0159784-9

Suttanon, P., Hill, K.D., Said, C.M., Byrne, K.N., \& Dodd, K.J. (2012). Factors influencing commencement and adherence to a home-based balance exercise program for reducing risk of falls: Perceptions of people with Alzheimer's disease and their caregivers. International Psychogeriatrics, 24(7), 1172-1182. PubMed ID: 22265269 doi:10. 1017/S1041610211002729

Suttanon, P., Hill, K.D., Said, C.M., Williams, S.B., Byrne, K.N., LoGiudice, D., . . . Dodd, K.J. (2013). Feasibility, safety and preliminary evidence of the effectiveness of a home-based exercise programme for older people with Alzheimer's disease: A pilot randomized controlled trial. Clinical Rehabilitation, 27(5), 427-438. PubMed ID: 23117349 doi:10.1177/0269215512460877

Teri, L., Gibbons, L.E., McCurry, S.M., Logsdon, R.G., Buchner, D.M., Barlow, W.E., . . . Larson, E.B. (2003). Exercise plus behavioral management in patients with Alzheimer disease-A randomized controlled trial. Journal of the American Medical Association, 290(15), 2015-2022. PubMed ID: 14559955 doi:10.1001/jama.290.15.2015

UK Data Archive. (n.d.). Create \& Manage Data: Anonymisation. Retrieved from http://www.data-archive.ac.uk/create-manage/consentethics/anonymisation?index $=2$

Van't Leven, N., Prick, A.E., Groenewoud, J.G., Roelofs, P.D., de Lange, J., \& Pot, A.M. (2013). Dyadic interventions for community-dwelling people with dementia and their family caregivers: A systematic review. International Psychogeriatrics, 25(10), 1581-1603. PubMed ID: 23883489 doi:10.1017/S1041610213000860

Watson, D., Clark, L.A., \& Tellegen, A. (1988). Development and validation of brief measures of positive and negative affect: The PANAS scales. Journal of Personality and Social Psychology, 54(6), 1063-1070. PubMed ID: 3397865 doi:10.1037/0022-3514.54.6. 1063

Wesson, J., Clemson, L., Brodaty, H., Lord, S., Taylor, M., Gitlin, L., \& Close, J. (2013). A feasibility study and pilot randomised trial of a tailored prevention program to reduce falls in older people with mild dementia. BMC Geriatrics, 13, 89. PubMed ID: 24004682 doi:10. 1186/1471-2318-13-89.

Woods, R.T., Orrell, M., Bruce, E., Edwards, R.T., Hoare, Z., Hounsome, B., . . . Russell, I. (2016). REMCARE: Pragmatic multi-centre randomised trial of reminiscence groups for people with dementia and their family carers: Effectiveness and economic analysis. PLoS ONE, 11(4), e0152843. PubMed ID: 27093052 doi:10.1371/journal. pone. 0152843

World Health Organization. (2012). Dementia: A public health priority. Retrieved from http://apps.who.int/iris/bitstream/10665/75263/1/ 9789241564458_eng.pdf?ua=1

World Health Organization. (2015). The epidemiology and impact of dementia: Current state and future trends. Retrieved from http:// www.who.int/mental_health/neurology/dementia/ dementia_thematicbrief_epidemiology.pdf

Wu, E., Barnes, D.E., Ackerman, S.L., Lee, J., Chesney, M., \& Mehling, W.E. (2015). Preventing Loss of Independence through Exercise (PLIE): Qualitative analysis of a clinical trial in older adults with dementia. Aging and Mental Health, 19(4), 353-362. PubMed ID: 25022459 doi:10.1080/13607863.2014.935290

Yao, L., Giordani, B.J., Algase, D.L., You, M., \& Alexander, N.B. (2012). Fall risk-relevant functional mobility outcomes in dementia following dyadic Tai Chi exercise. Western Journal of Nursing Research, 35(3), 281-296. PubMed ID: 22517441 doi:10.1177/0193945912443319

Yardley, L., Bishop, F.L., Beyer, N., Hauer, K., Kempen, G.I.J.M., Piot-Ziegler, C., . . . Holt, A.R. (2006). Older people's views of falls-prevention interventions in six European countries. The Gerontologist, 46(5), 650-660. Retrieved from https://www.research. manchester.ac.uk/portal/files/29912088/POST-PEER-REVIEWPUBLISHERS.PDF

Yu, F., Thomas, W., Nelson, N.W., Bronas, U.G., Dysken, M., \& Wyman, J.F. (2015). Impact of 6-month aerobic exercise on Alzheimer's symptoms. Journal of Applied Gerontology, 34(4), 484-500. PubMed ID: 24652914 doi:10.1177/0733464813512895 